American Journal of Applied Sciences 8 (1): 55-62, 2011

ISSN 1546-9239

(C) 2010 Science Publications

\title{
Voltage Swells Improvement in Low Voltage Network Using Dynamic Voltage Restorer
}

\author{
${ }^{1}$ R. Omar, ${ }^{2}$ N.A. Rahim and ${ }^{1}$ A. Ahmad \\ ${ }^{1}$ Deparment of Industrial Power, Faculty of Electrical, \\ University Technical Malaysia Melaka, Malaysia \\ ${ }^{2}$ UMPEDAC, Faculty of Engineering, University of Malaya, \\ 50600 Kuala Lumpur, Malaysia
}

\begin{abstract}
Problem statement: Voltage disturbances are the most common power quality problem due to the increased use of a large numbers of sophisticated electronic equipment in industrial distribution system. The voltage disturbances such as voltage sags, swells, harmonics, unbalance and flickers. High quality in the power supply is needed, since failures due to such disturbances usually have a high impact on production cost. There are many different solutions to compensate voltage disturbances but the use of a DVR is considered to be the most cost effective method. The objective of this study is to propose a new topology of a DVR in order to mitigate voltage swells using a powerful power custom device namely the Dynamic Voltage Restorer (DVR). Approach: New configuration of a DVR with an improvement of a controller based on direct-quadrature-zero method has been introduced to compensate voltage swells in the network. Results: The effectiveness of the DVR with its controller were verify using Matlab/Simulink's SimPower Toolbox and then implemented using 5KVA DVR experimental setup. Simulations and experimental results demonstrate the effective dynamic performance of the proposed configuration. Conclusion: The implimentation of the proposed DVR validate the capabilities in mitigating of voltage swells effectiveness.During voltage swells, the DVR injects an appropriate voltage to maintain the load voltage at its nominal value.
\end{abstract}

Key words: Dynamic Voltage Restorer (DVR), Voltage Source Inverter (VSI), Insulated Gate Bipolar Transistors (IGBTs), Fast Fourier Transform (FFT), Voltage Total Harmonic Distortion (VTHD), Low Pass Filter (LPF)

\section{INTRODUCTION}

Recently, the growth in the use of sensitive loads in all industries has caused many disturbances such as voltage sags, swells, transient and unbalance. These types of disturbances which caused malfunction or shut down and tend to revenue losses. Several methods are available to prevent equipment malfunction due to voltage swells. One of commonly used methods is the use of series voltage controller, DVR, to mitigate voltage swells condition (Perera, 2007).

DVR is an important tool to mitigate disturbances related to power quality problems in the distribution network. One of the crucial disturbances in the electrical network is voltage swells. The existing DVR as shown in Fig. 1, consists of a Voltage Source Inverter (VSI), series injection transformer, filtering scheme and an energy storage device may that be connected to the dc-link (Perera, 2007; Kumar and Nagaraju, 2007).
Voltage sags/swells can occur more frequently than other power quality phenomenon. These sags/swells are the most important power quality problems in the power distribution system. IEEE 519-1992 and IEEE 1159-1995 describe the voltage sags/swells as shown in Fig. 2 (IEEE Standards Board, 1995; Perera, 2007; Kumar and Nagaraju, 2007; Banaei et al., 2006a).

In this study the proposed new configuration is shown to posses the ability of mitigating voltage swells in low voltage distribution systems. The capacity of the developed device is about 5KVA. This prototype is evaluated and tested in the laboratory and later it will be tested in the industry.

\section{MATERIALS AND METHODS}

The study also addresses the new technique of DVR controller in order to compensate voltage swells in low voltage distribution system. The proposed controller shows the capability of mitigating voltage swell effectively.

Corresponding Author: R. Omar, Deparment of Industrial Power, Faculty of Electrical, University Technical Malaysia Melaka, Malaysia 
Am. J. Applied Sci., 8 (1): 55-62, 2011

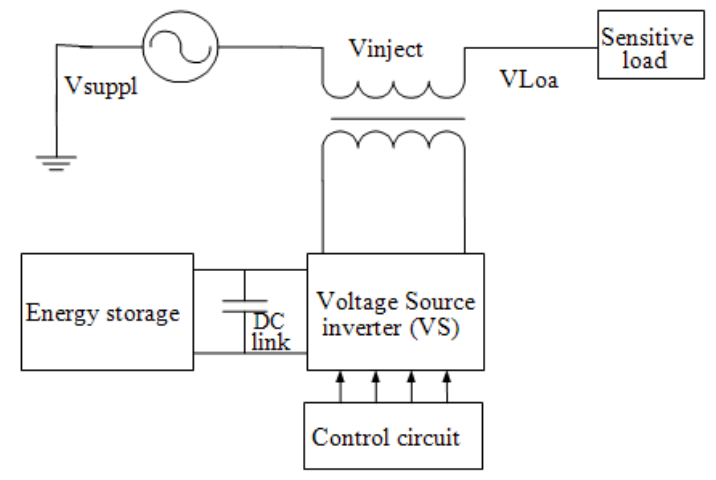

Fig. 1: Schematic diagram of Conventional DVR

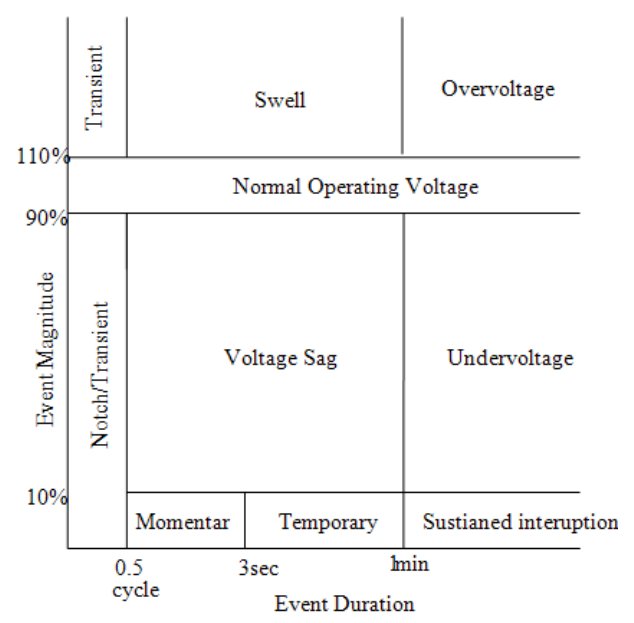

Fig. 2: Voltage Reduction Standard of IEEE Std 11591995

The entire sections of this study is divided into four sections. Description of DVR and explaination of its functioning are discussed in section I. Section II describes a new configuration of DVR's controller. The Simulation results are discussed in Section III. Finally the experimental results obtained are presented in section IV.

DVR is connected in series between the source voltage or grid and sensitive loads through injection transformer. There are several types of energy storage been used in the DVR such as battery, superconducting coil and flywheels. These types of energy storages are very important in order to supply active and reactive power to DVR. The controller is an important part of the DVR for switching purposes. The switching converter is responsible to do conversion process from DC to AC. The inverter ensures that only the swells or sags voltage is injected to the injection transformer $(\mathrm{Li}$ et al., 2001; Benachaiba and Ferdi, 2009; Ezoji et al., 2009; Zhan et al., 2001). Which has a VSI and the injection transformer. The VSI consists of six Insulated Gate Bipolar Transistors (IGBTs), three ac inductors and capacitors, one dc capacitor and energy storage. The selection of IGBT's, interfacing inductor; $\mathrm{dc}$ capacitor and the filter are as per the design for a dynamic voltage restorer (Fitzer et al., 2002; Quirl et al., 2006; Kumar and Nagaraju, 2007). In order to protect DVR from any disturbances a hybrid switch being used in which its operation will be discussed later.

As stated earlier, the function of DVR is to inject the difference voltages between the voltage source and the sensitive load. The sources of injection voltages are available from the energy storage device which is capable to supply real and reactive power. The DC energy storage rating determines the maximum injection capability of the DVR. The injection transformer consists of the high and low voltages side. The booster voltages can occur through injection transformer which consists of high and low voltages. The source supply is connected in series with the high voltage side where as the converter is connected at the voltage side (TMS, 2007).

The New Proposed Configuration Of DVR: The new configuration of the proposed DVR is shown in Fig. 4. This new configuration utilizes the three single phase of the injection transformer. The injection transformer can be connected either in delta/open or star/open configuration. In this research the series injection transformer was configured as delta/open. The DVR power circuit consists of the 3-leg inverter which has 6 IGBT switches and the battery as a dc energy storage.

Harmonics produced by the VSI of a DVR must be eliminated through proper filtering scheme installation on the DVR. In the designed of the DVR filter components consists of capacitor, inductance and resistance. Filters components can be installed either on the high voltage or the low-voltage side of the injection transformer and are referred to as line side filter and inverter-side filter respectively (Banaei et al., 2006b).

The type of this filtering configuration can also eliminate switching ripples produced by the converter. The type of this filtering configuration can also eliminate switching ripples produced by the converter. As for the filtering configuration is placed in the high voltage side. In this case, high order harmonic currents will penetrates through the injection and it will carry the harmonic voltages. When compensating for the voltage swells at the critical load, the DVR produces a harmonic distortion fed from the series transformer as an injection voltage to the critical load. Using a Fast Fourier Transform (FFT) analyzer to measure the Voltage Total Harmonic Distortion (VTHD) of the filtering scheme, it is found that the VTHD value is $1.4 \%$ and is satisfies the IEEE519 standard harmonic voltage limit. 


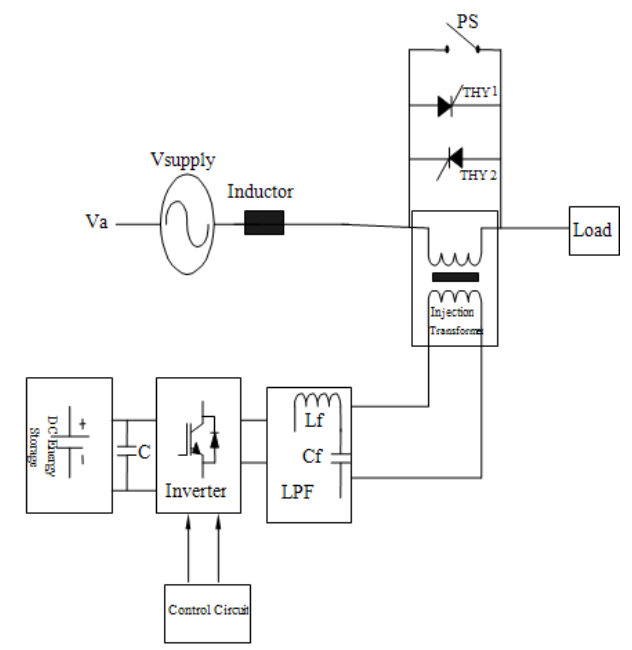

Fig. 3: Shows the existing topology of the DVR

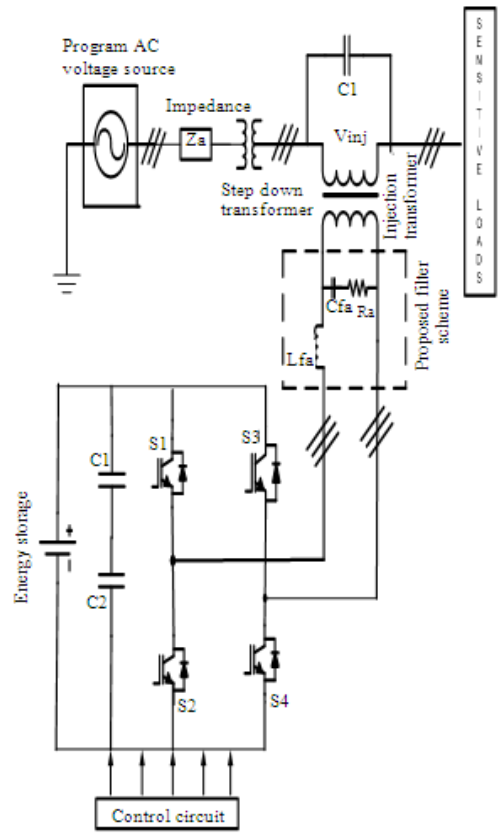

Fig. 4: The Proposed Configuration of DVR

The control of DVR system: There are many control schemes reported in the literature for control of DVR such as instantaneous reactive power theory, power balanced theory, synchronous reference frame theory etc (14). In this study a new control method for DVR system is proposed by using the d-q-o transformation or Park's transformation for sags/swells detection. The dq-o method gives the sag depth and phase shift information with start and end times. The main aspects of the control system are shown in Fig. 5 and include the following blocks.
Block 1 is used to convert the three phase load voltages $\left(\mathrm{V}_{\mathrm{La}}, \mathrm{V}_{\mathrm{Lb}}, \mathrm{V}_{\mathrm{Lc}}\right)$ into the $\alpha-\beta$-o coordinates as in equation (1).

$$
\left[\begin{array}{c}
\mathrm{V}_{\alpha} \\
\mathrm{V}_{\beta} \\
\mathrm{V}_{\mathrm{o}}
\end{array}\right]=\mathrm{Q}\left[\begin{array}{c}
\mathrm{V}_{\mathrm{La}} \\
\mathrm{V}_{\mathrm{Lb}} \\
\mathrm{V}_{\mathrm{Lc}}
\end{array}\right]
$$

Where $Q=\frac{2}{3}\left[\begin{array}{ccc}1 & \frac{-1}{2} & \frac{-1}{2} \\ 0 & \frac{\sqrt{3}}{2} & \frac{-\sqrt{3}}{2} \\ \frac{1}{2} & \frac{1}{2} & \frac{1}{2}\end{array}\right]$

Block 1 is used to convert the three phase load voltages $\left(\mathrm{V}_{\mathrm{La}}, \mathrm{V}_{\mathrm{Lb}}, \mathrm{V}_{\mathrm{Lc}}\right)$ into the $\alpha-\beta$-o coordinates as in equation (1), the three phase load voltages reference components $\mathrm{V}_{\alpha \text {-ref, }} \mathrm{V}_{\alpha \text {-ref }}$ and $\mathrm{Vo}_{\text {ref }}$ can be converted to $\mathrm{V}_{\mathrm{d} \text { ref }}$ and $\mathrm{V}_{\mathrm{q} \text { ref }}(2)$.

$\left[\begin{array}{c}\mathrm{V}_{\mathrm{d}} \\ \mathrm{V}_{\mathrm{q}}\end{array}\right]=\frac{2}{3}\left[\begin{array}{ll}\cos \theta & \sin \theta \\ \sin \theta & \cos \theta\end{array}\right]\left[\begin{array}{c}\mathrm{V}_{\alpha} \\ \mathrm{V}_{\beta}\end{array}\right]$

Transformation to dqo to abc:

$$
\begin{aligned}
& {\left[\begin{array}{c}
\mathrm{V}_{\alpha} \\
\mathrm{V}_{\beta}
\end{array}\right]=\frac{2}{3}\left[\begin{array}{lll}
\cos \theta & \sin \theta \\
\sin \theta & \cos \theta
\end{array}\right]\left[\begin{array}{c}
\mathrm{V}_{\mathrm{d}} \\
\mathrm{V}_{\mathrm{q}}
\end{array}\right]} \\
& {\left[\begin{array}{c}
\mathrm{V}_{\mathrm{a}} \\
\mathrm{V}_{\mathrm{b}} \\
\mathrm{V}_{\mathrm{c}}
\end{array}\right]=\left[\begin{array}{lll}
1 & 0 & 1 \\
-0.5 & \frac{\sqrt{3}}{2} & 1 \\
-0.5 & \frac{\sqrt{3}}{2} & 1
\end{array}\right]\left[\begin{array}{c}
\mathrm{V}_{\alpha} \\
\mathrm{V}_{\beta} \\
\mathrm{V}_{\mathrm{o}}
\end{array}\right]}
\end{aligned}
$$

Block 2 is considered as a source voltages $\left(\mathrm{V}_{\mathrm{sa}}, \mathrm{V}_{\mathrm{sb}}\right.$, $\left.\mathrm{V}_{\mathrm{sc}}\right)$. The amplitude of $\mathrm{AC}$ voltage at the sources $\left(\mathrm{V}_{\text {source }}\right)$ can be calculated as follow:

$$
\mathrm{V}_{\text {source }}=\frac{2}{3}\left(\sqrt{\left(\mathrm{V}_{\mathrm{sa}}\right)^{2}+\left(\mathrm{V}_{\mathrm{sb}}\right)^{2}+\left(\mathrm{V}_{\mathrm{sc}}\right)^{2}}\right)
$$

Block 3 is a three phase PLL (Phase-locked loop). The angle $\theta$ of the source voltage can be obtained using 

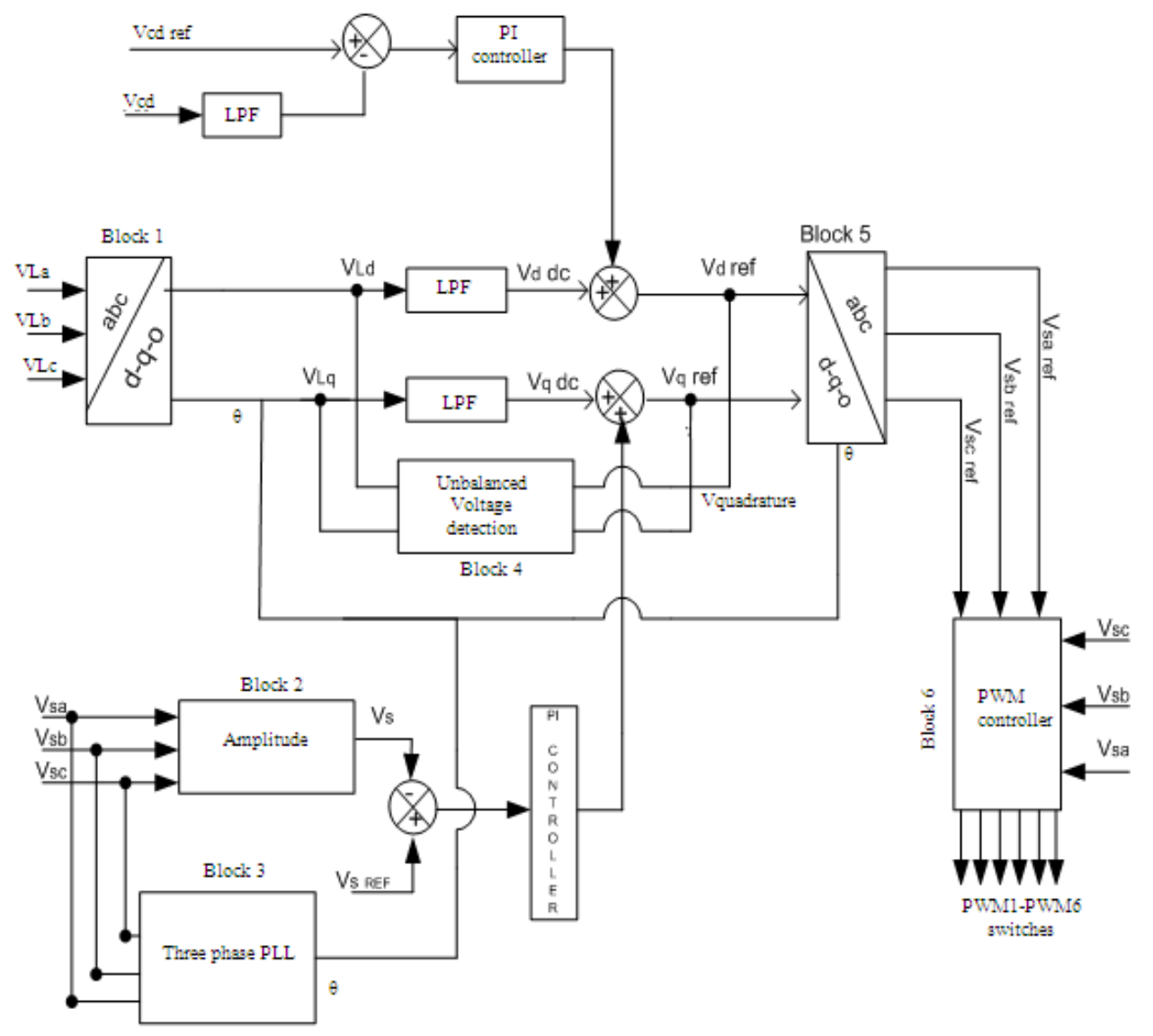

Fig. 5: Block diagram control scheme of DVR for voltage swells

three phase PLL. The information extracted from the PLL is used for detection and reference voltage generation.

Block 4 is the detection scheme for the voltage Unbalanced compensator. From Fig. 5 shows that, the synchronous frame variables, $\mathrm{V}_{\mathrm{d}}$ and $\mathrm{V}_{\mathrm{q}}$ are used as inputs for low pass filters to generate voltage references in the synchronous frame.

Block 5 receive the components of the load voltage vectors $\mathrm{V}_{\mathrm{d}}$ ref and $\mathrm{V}_{\mathrm{q}}$ ref and transforms them to three phase coordinates using equation (3) and (4) the generation voltages are used as the voltage reference. The DC link error in Fig. 5 is used to get optimized controller output signal because the energy on the DC link will be changed during the unbalance voltage.

Block 6 is the PWM block, this block provides the firing for the Inverter switches (PWM1 to PWM6). The injection voltage is generated according to the difference between the reference load voltage and the supply voltage and is applied to the Voltage Source Inverter (VSI).
Table 1: System parameter

\begin{tabular}{ll}
\hline Parameter & Value \\
\hline Nominal grid voltage & $200 \mathrm{~V}(\mathrm{~L}-\mathrm{L})$ \\
Nominal load voltage & $120 \mathrm{~V}(\mathrm{~L}-\mathrm{L})$ \\
Maximum series voltage Injection & $100 \mathrm{~V}(\mathrm{~L}-\mathrm{L})$ \\
Switching/sampling frequency & $10 \mathrm{KHz}$ \\
Max. inverter dc-bus voltage & $120 \mathrm{~V}$ \\
Capacitor of dc- bus & $26 \mathrm{uF}$ \\
Filter inductance & $2.7 \mathrm{mF}$ \\
Filter capacitance & $50 \mathrm{uF}$ \\
\hline
\end{tabular}

The function of the Low Pass Filter (LPF) in Fig. 4 is to eliminate the harmonics and the oscillatory component of the voltage.

MATLAB based simulation of DVR System: The proposed control scheme for the DVR is validated in this section via MATLAB/SIMULINK Sim Power System toolbox. In this study, the load is represented by a series equivalent rated at $200 \mathrm{~V}, 5 \mathrm{KVA}$ at 0.9 load power factor. A simulation model has been developed in MATLAB/SIMULINK as shown in Fig. 4. Simulation and experimental parameters are given in Table 1. The performance of the DVR for different 
Am. J. Applied Sci., 8 (1): 55-62, 2011

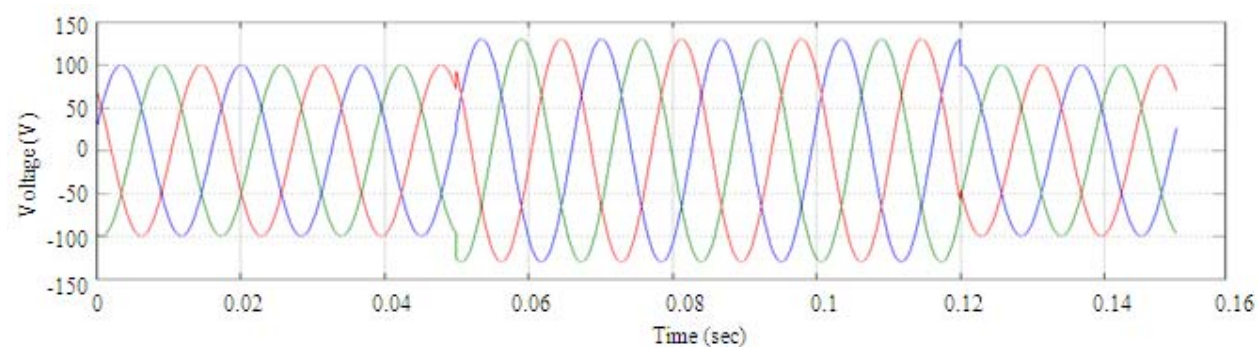

(a)

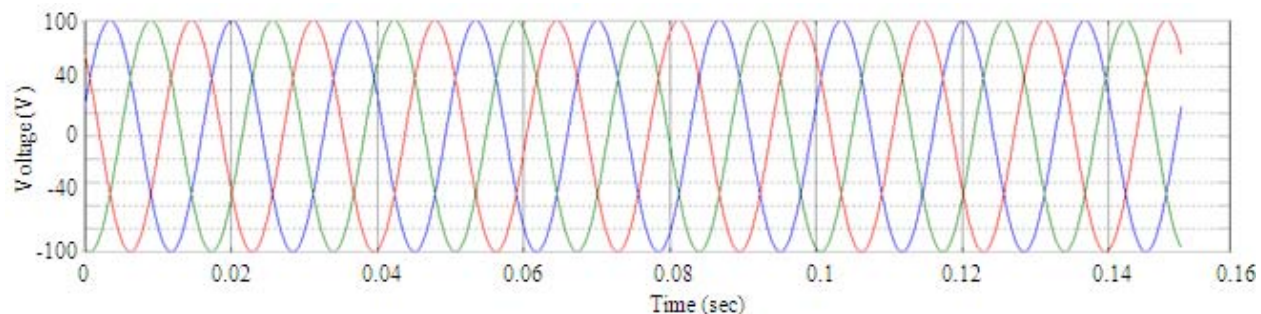

(b)

Fig. 6: (a) Balanced voltage swells (b) Load voltage after restoration

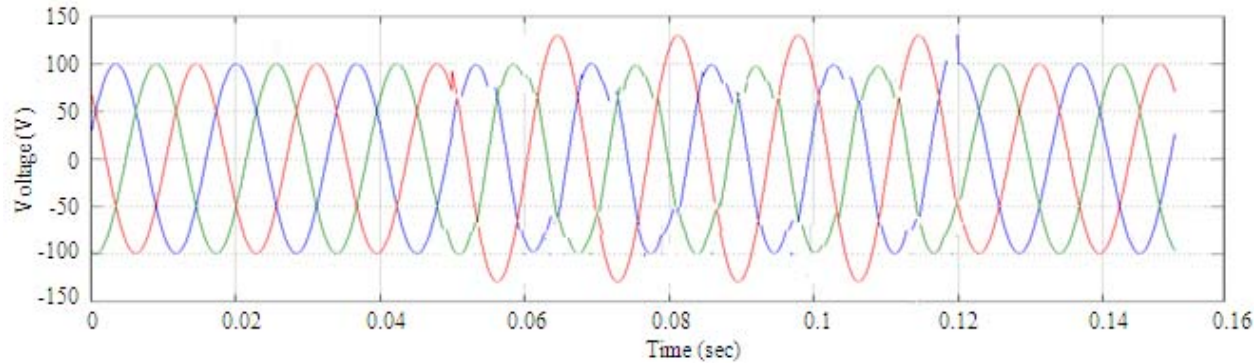

(a)

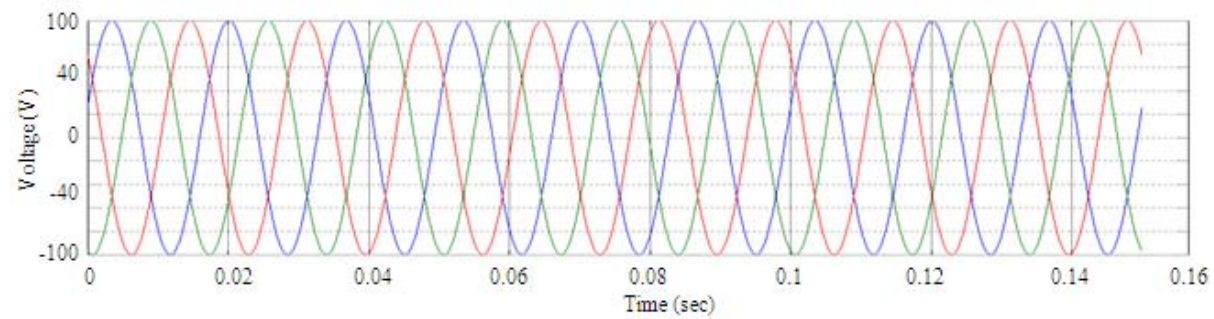

(b)

Fig. 7: (a) One phase voltage swells (b) Load voltage after restoration

supply disturbances is tested under various operating conditions. Several simulation of the DVR with proposed controller scheme and new configuration of it have been made.

System parameter: Investigation on the DVR performance can be observed through testing under various disturbances condition on the source voltage.
The proposed control algorithm was tested for balanced and unbalanced voltages swells in the low voltage distribution system. In case of balance voltage swell, the source voltage has increased about $20-25 \%$ of its nominal value. The simulation results of the balance voltage swells as shown in Fig. 6a. The swells voltages occur at the time duration of $0.06 \mathrm{~s}$. Then after $0.12 \mathrm{~s}$ the voltage will restore back to its normal value. The DVR 
voltage $\mathrm{V}_{\mathrm{DVR}}$ is injected in series with the feeder to mitigate for voltage swells and maintain undisturbed load. The restore voltage at the load side can be seen in Fig. 6(b). The Figure shows the effectiveness of the controller response to detect voltage swells quickly and inject an appropriate voltage.

A voltage swell can occur due to a single-line to ground fault on the network, which can also caused in a temporary voltage rise on the unfaulted phases, one of the phase of voltage has increased around $20-25 \%$ with duration time of is $0.06 \mathrm{~s}$ Fig. 7a. The swells voltage will stop after $0.12 \mathrm{~s} \mathrm{Fig.} 7 \mathrm{~b}$. At this stage the DVR will injects the missing voltage in order to compensate it and the voltage at the load will be protected from voltage swells problem.

\section{RESULTS AND DISCUSSION}

In order to verify the effectiveness of the proposed system, a 5KVA hardware prototype has been built based on the new configuration of DVR. Fig. 3 describes the system configuration of the developed prototype. The mains supply is three phase, $50 \mathrm{~Hz}$, $120 / 120 \mathrm{~V}$ and the turn ratio of the series transformer is $1: 1$. The switching frequency of the inverter is $5 \mathrm{kHz}$. The filtering capacitor and inductor are $50 \mathrm{uF}$ and $2.7 \mathrm{mH}$ respectively. To start up the test, the loads are first powered by the utility, the low voltage prototype DVR was fed with a programmable AC power source $6560 / 6590$. The prototype is rated to protect 5KVA load with $25 \%$ voltage swells from their nominal voltage. All the components part of the DVR has been integrated according to the parameters in the Table 1. A DSP TMS320F2812 board was used for the control scheme. The sampling frequency is set at $10 \mathrm{kHz}$. The source voltages $\mathrm{V}_{\mathrm{sa}}, \mathrm{V}_{\mathrm{sb}}, \mathrm{V}_{\mathrm{sc}}$ are measured by the voltage sensor, then its signals are entered into the DSP board. The output currents of the inverter is measured by using current sensor and then sensed by the DSP board to boost up the voltage response of the DVR. In the experiment, a $25 \%$ three phase and single phase swells are generated from their nominal voltage. The experimental results obtained for both conditions are shown in Fig. 8 and 9 respectively.

Figure $8 \mathrm{a}$ shows the waveform of utility voltage when the tested system suffered a disturbance of $25 \%$ voltage swell. Balanced voltage swells are created immediately after a fault. The DVR injects fundamental voltage in series with the supply voltage. Fig. 8b shows the load terminal voltages which are restored through the compensation by DVR.

Next, the performance of DVR for one single phases to ground fault is also investigated. Fig. 9a shows the series of voltages components for unbalanced conditions for one phase to ground fault. The DVR load voltages voltages are shown in Fig. 9b. From the results, the swells load terminal voltage is restored and help to maintain a balanced and constant load voltage.

Figure $8 \mathrm{~b}$ and $9 \mathrm{~b}$ illustrate the voltage restoration performances of the DVR during the source side three phase and one phase voltage swells respectively. As can be seen from the figures, the voltage at sensitive load is maintained to constant magnitude.

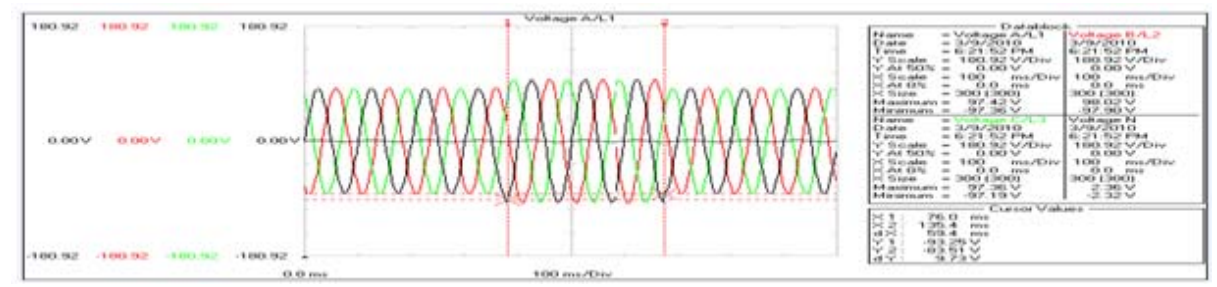

(a)

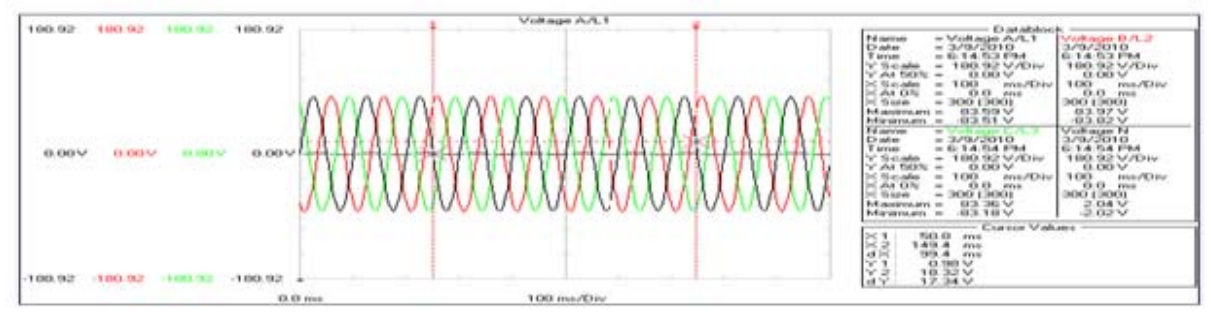

(b)

Fig. 8: (a) Three phase voltage swell (b) Load voltage after restoration 


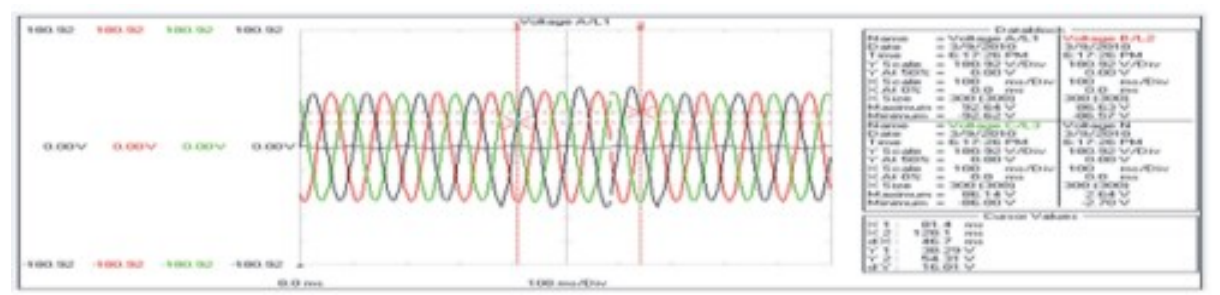

(a)

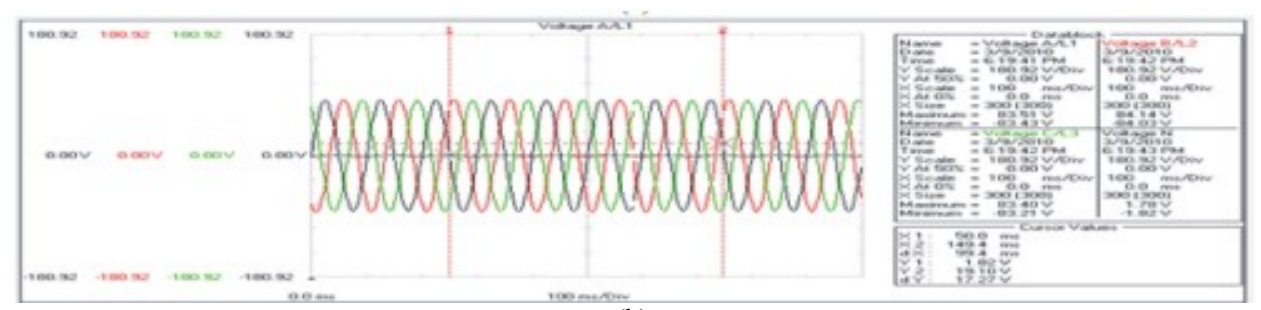

(b)

Fig. 9: (a) One phase voltage swells (b) Load voltage after restoration

\section{CONCLUSION}

A new compensation voltage control scheme was proposed in this study. This study discusses the aspect related with the specification and control of the DVR for voltage swell mitigation in low voltage distribution network. The proposed method can protect customer's equipment from potential voltage swells. The strength of the topology was proven with several simulation and experimental results. These results validate the proposed strategy for the detection and control of the DVR. The results also show that the DVR compensation is fast and the source voltage fault can be compensated by series voltage injection transformer.

\section{ACKNOWLEDGEMENT}

The authors wish to thank UM and UTeM for providing grant under grant PS002/2007B for this project.

\section{REFERENCES}

Banaei, M.R., S.H. Hosseini and G.B. Gharehpetian, 2006a. Inter-line dynamic voltage restorer control using a novel optimum energy consumption strategy. Simulation Modell. Prac. Theory, 14: 989-999. DOI: 10.1016/j.simpat.2006.06.001

Banaei, M.R., S.H. Hosseini, S. Khanmohamadi and G.B. Gharehpetian, 2006b. Verification of a new energy control strategy for dynamic voltage restorer by simulation. ELSEVIER Simulation Model. Practice Theory, 14: 112-125. DOI: 10.1016/j.simpat.2005.03.001
Benachaiba, C. and B. Ferdi, 2009. Power quality improvement using DVR. Am. J. Applied Sci., 6: 396-400.

Ezoji, H., A. Sheikholeslami, M. Tabasi and M.M. Saeednia, 2009. Simulation of dynamic voltage restorer using hysteresis voltage control. European J. Sci. Res., 27: 152-166.

Fitzer, C., A. Arulampalam, M. Barnes, R. Zurowski, 2002. Mitigation of saturation in dynamic voltage restorer connection transformers. IEEE Trans. Power Elect., 17: 1058-1066. DOI: 10.1109/TPEL.2002.805584

IEEE Standards Board, 1995. IEEE Recommended Practice for Monitoring Electric Power Quality. IEEE Inc. New York, ISBN: 1559375493, pp: 70.

Kumar, S.V.R. and S.S. Nagaraju, 2007. Simulation of d-statcom and DVR in power systems. ARPN J. Eng. Applied Sci., 2: 7-13.

Li, B.H., S.S. Choi and D.M. Vilathgamuwa, 2001. Design considerations on the line-side filter used in the dynamic voltage restorer. IEE Proc. Generat. Trans. Distribut., 148: 1-7. DOI: 10.1049/ipgtd:20010017

Perera, M.V.K., 2007. Control of a Dynamic Voltage Restorer to Compensate Single Phase Voltage Sags. Master of Science Thesis Stockholm, Sweden. http://www.docstoc.com/docs/43551112/Controlof-a-Dynamic-Voltage-Restorer-to-compensate-single

Quirl, B.J., B.K. Jhonson and H.L. Hess, 2006. Mitigation of voltage sags with phase jump using a dynamic voltage restorer. Proceeding of the 38th Power Symposium, Sept. 17-19, Carbondale, IL, North American, pp: 647-654. 
Am. J. Applied Sci., 8 (1): 55-62, 2011

TMS, 2007. 320C281x Event Manager Reference Guide. Texas Instrument. http://focus.ti.com/lit/ug/spru065e/spru065e.pdf

Zhan, V.K.R., A.A. Rulampalam and C.F. Barnes, 2001. Dynamic voltage restorer based on voltage space vector PWM control. Proceeding of the IEEE 16th Annual Applied Power Electronics Conference and Exposition, Mar. 4-8, Anaheim, CA, USA., pp: 1301-1307. DOI: 10.1109/APEC.2001.912533 